This study has confirmed the possibilities of using logging waste for the production of wood-composite material. The raw material for its manufacturing is the wood weaving made by flattening branches. An experimental study into the physical, mechanical, and technological properties of the wood-composite material made from the poplar branches has made it possible to determine its rational structure and the type of a binder. It has been established that ensuring the flat shape of the material requires that it should be formed of three mutually perpendicular layers. It is advisable to use urea formaldehyde resin as a binder for plates that are not exposed to the impact and static loads and are used indoors. When the material is to be applied under conditions of elevated loads and in places with high humidity, phenol-formaldehyde resin should be used. The rational pressing schedule parameters have been defined: temperature, $t=180^{\circ} \mathrm{C}$; pressure, $p=8 \mathrm{MPa}$; holding time, $\tau=7$ min., at which one can achieve a minimum deformation of plates after pressing. It has been proven that under these schedule parameters the holding time for the new wood-composite material to achieve the shape stabilization is also minimal; it is seven days. It has been determined that the new wood-composite material possesses the physical and mechanical properties similar to those of the OSB panels

Keywords: wood-composite materials, logging waste, poplar branches, pressing schedule, shape stabilization time
UDC 674.11

DOI: $10.15587 / 1729-4061.2020 .209130$

\title{
DESIGNING A NEW WOOD- COMPOSITE MATERIAL MADE FROM LOGGING WASTE
}

\author{
O. Pinchevska \\ Doctor of Technical Sciences, Professor* \\ E-mail: olenapinchevska@nubip.edu.ua \\ Y u . L a k yda \\ $\mathrm{PhD*}$ \\ O. Baranova \\ $\mathrm{PhD}$ * \\ M. Biletskyi \\ $\mathrm{PhD}$ * \\ V. Holovach \\ $\mathrm{PhD}$, Senior Researcher
}

Department of Energy Audit and Energy Saving Ukrainian State Research Institute «Resource» Malevich str., 84, Kyiv, Ukraine, 03150

R. O I i in y k

$\mathrm{PhD}$, Associate Professor Department of Meteorology and Climatology Department Taras Shevchenko National University of Kyiv Volodymyrska str., 64/13, Kyiv, Ukraine, 01033

A. Yeroshenko

$\mathrm{PhD}$

Department of Mechanical Engineering and Wood Technology

Chernihiv National University of Technology

Shevchenka str., 95, Chernihiv, Ukraine, 14035

*Department of Technology and Design of Wood Products National University of Life and Environmental Sciences of Ukraine

Heroiv Oborony str., 15, Kyiv, Ukraine, 03041

Copyright (c) 2020, O. Pincherska, Yu. Lakyda,

O. Baranova, M. Biletskyi, V. Holovach, R. Oliinyk, A. Yeroshenko

This is an open access article under the CC BY license (http://creativecommons.org/licenses/by/4.0)

\section{Introduction}

One of the biggest environmental problems, which has been particularly acute in any industry in recent years, is the formation of significant volumes of different types of wastes and, therefore, the necessity of their storage, processing, and utilize.

At present, woodworking and logging enterprises also face the issue related to the disposal of wood waste because timber harvesting leaves up to $25 \%$ of the biomass in the felling area; its use is a pressing problem.

Over years, there is an increasingly acute task to efficiently and completely utilize wood, including timber waste. In 2019 alone, the amount of waste from timber harvesting operations in Ukraine amounted to about 9 million $\mathrm{m}^{3}$; it was mostly piled in felling areas (tree tops, knots, branches, rotten parts of trees, etc.) and subsequently burned.
One of the most effective ways to utilize the wastes of logging and woodworking is to use them in the production of wood-composite materials. The manufacturing technology of fiberboards of different densities, particle boards, oriented strand boards involves the crushed fibers of wood waste [1].

This predetermines their use in the furniture industry and in the carpentry and construction sector. Production of the latter in Ukraine is insignificant because of the difficulties related to equipment and the inability to directly utilize all the waste from timber-woodworking enterprises, which requires the search for alternative solutions. Another way to use wood waste is the production of fuel briquettes and granules. This is relevant due to the high cost and non-sustainability of traditional heat sources. However, this production is currently unprofitable as there is fierce competition among the manufacturers of timber-based panels and energy to purchase the raw materials [2]. As regards logging waste, 
its significant part is those branches that are not used in the manufacture of fuel due to the large content of bark. The development of a technology for the rational use of branches as a wood component for wood-plate materials may be an alternative to structural materials available in the market, given that the raw materials' cost in the felling area is negligible.

Therefore, determining the technological features in the manufacture of a wood-composite material from logging waste is not only of the scientific and practical significance but could also ensure the rational utilization of wood resources to produce products with a high added value.

\section{Literature review and problem statement}

The utilization of wood waste is addressed in the studies that consider the production of plate materials by pressing when using various binders [3-5]. Their authors established the possibility to receive plate materials using environmentally-friendly adhesives. However, the wood component used was crushed timber, which makes it impossible to apply these results for other types of wood raw materials. Work [6] describes a manufacturing technology and the properties of wood particle boards (WPB) while defining the requirements to the size of a wood component - chips. It is recommended to use chips of the following sizes: thickness, $0.2-0.5 \mathrm{~mm}$; width, $1-10 \mathrm{~mm}$; length, $5-40 \mathrm{~mm}$. In addition, the authors determined the physical and mechanical properties and examined the advantages of WPB and the medium density fiberboards (MDF). They compared their properties with massive timber. However, such issues as the environmental friendliness, low tensile strength, moistureand thermolability, which restrict their use in construction, remained unresolved. The use of certain additives to the binder, contributing to binding formaldehyde and various types of finishing, which enhance environmental friendliness, contributed to the wide application of WPB and MDF in the production of structural furniture. However, given an insignificant value of the tensile strength limit $(10-27 \mathrm{MPa})$, the use of WPB and MDF plates as countertops is limited to the corresponding dimensions and requires reinforcement in the form of additional supports [7].

The low bending strength of the above plate materials is due to the insignificant size of wood particles, which, unlike timber whose structure is formed during the natural growth, lose their strength characteristics [8]. The influence of the shape and size of wood particles, as well as their arrangement in the plate, on the mechanical properties of wood-composite materials was tackled by many studies [8,9], whose authors made a conclusion about the expediency of choosing an orientation way and increasing the size of wood particles (for length, $75-150 \mathrm{~mm}$; for width, $15-25 \mathrm{~mm}$ ). That was implemented in the oriented strand boards (OSB), which made it possible to increase their tensile strength to $18-28 \mathrm{MPa}$ [10]; however, the tensile strength compared to massive timber was not achieved. In addition, the manufacturing technology of WPB, MDF, and OSB restricts the use of bark - up to $4 \%$.

The desire to preserve the natural strength of wood fibers was reproduced in such materials as Ultraspen, Stractureframe, Scrimber [11], and «Monodrev» [12], which allowed a three-time increase in rigidity compared to WPB. However, in all the materials for the production of a wood component used tree trunks of small diameters, which does not solve the issue of the use of logging waste, namely branches.
The uncertainty related to the utilization of branches, whose specific content of bark is significant, and the necessity to develop a technological regulation on the production of wood-composite material from them, predetermine our research in this area.

\section{The aim and objectives of the study}

The aim of this study is to scientifically substantiate the composition of a new composite material that includes a wood component to preserve the integrity of the fibers.

To accomplish the aim, the following tasks have been set:

- to determined a priority binder for the production of a new composite material from flattened branches;

- to define the parameters of a wood component obtained by a flattening method and the technological stages in the manufacture of wood-composite material based on them;

- to determine a shape stabilization time of the panels made from the new composite material.

\section{Materials and methods of research in the development of a wood-composite material from logging waste}

\subsection{The study materials used in the experiment}

To perform the research, we used the following materials:

- the samples of poplar wood, $1 \mathrm{~m}$ long, a diameter from $15 \mathrm{~mm}$ to $30 \mathrm{~mm}$, a $95 \%$ moisture content;

- the urea formaldehyde low-toxic resin, brand KFM-MT-15;

- phenol-formaldehyde resin, brand Lignofen.

To flatten branches, we used an experimental modernized installation (Fig. 1), where the branches were flattened to obtain the weaving of fibers, conditionally divided into the «thin» fibers with a thickness of 1 to $5 \mathrm{~mm}$ and the «thick» ones, a thickness of 6 to $10 \mathrm{~mm}$ (Fig. 2).

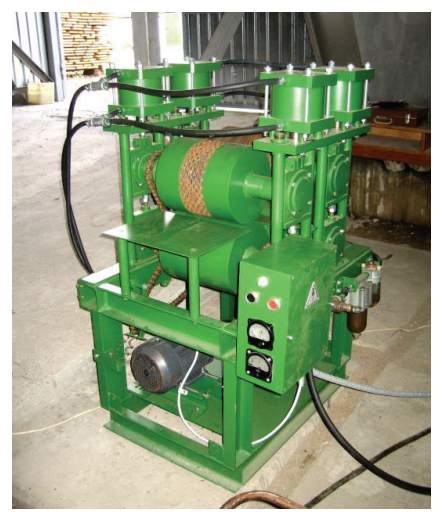

Fig. 1. Experimental installation to flatten branches [13]

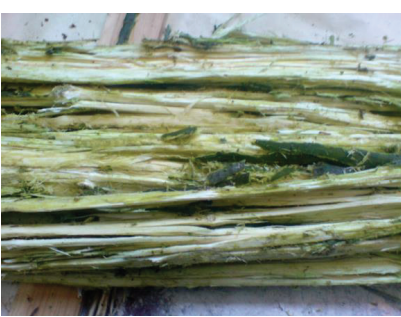

$a$

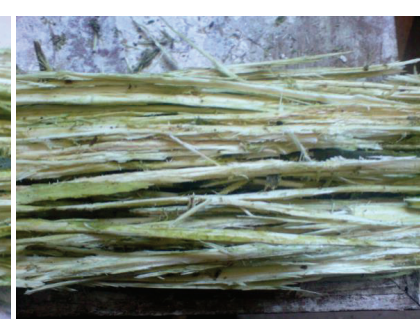

$b$
Fig. 2. The weaving of fibers obtained after flattening: $a-$ «thin» fibers, $b-$ «thick» fibers [13] 
The samples of fibers in the weave were dried to a moisture content of $4 \%$, tarred by the contact method with a binder content of $12 \%$ (\% to the mass of a wood component), and placed in a mold. Assembled packages were first pressed in the press with cold plates PMM-125, followed by pressing in the press with heating plates MS-2000. The pressing pressure was $p=8 \mathrm{MPa}$, the temperature and holding time of the urea formaldehyde-based resin were $t=180^{\circ} \mathrm{C}$, $\tau=7 \mathrm{~min}$; for panels that contained phenol-formaldehyde resin, correspondingly, $t=200{ }^{\circ} \mathrm{C}, \tau=8 \mathrm{~min}$. The result of the pressing process was the new wood-composite material in the form of panels, the size of $330 \times 330 \mathrm{~mm}$. The panels had different orientations, and dimensions of the fibers in the weave, as well as the number of layers. These panels were then used to manufacture the samples for determining the physical and mechanical properties.

The density and water absorption experiments, according to [14,15], were conducted using samples of the following size: length, $100 \mathrm{~mm}$; width, $100 \mathrm{~mm}$; thickness, $15 \mathrm{~mm}$. To determine the tensile strength and elasticity module at bending according to [16], samples of the following size were used: length, $350 \mathrm{~mm}$; width, $50 \mathrm{~mm}$; thickness, $15 \mathrm{~mm}$. For determining the impact viscosity, samples of the following size were used: length,130 mm; width, $20 \mathrm{~mm}$; thickness, $15 \mathrm{~mm}$. The specific resistance against pulling out nails was determined on samples of the following size: length, $50 \mathrm{~mm}$; width, $50 \mathrm{~mm}$; thickness, $15 \mathrm{~mm}$.

\section{2. Procedure for determining the rational design and} the binder for wood-composite material

The rational design and a priority binder were chosen experimentally. In the first stage of the research, four types of panels with different sets of layers were made:

a) a three-layer panel with parallel fiber arrangement, outer layers are from the «thin» fibers, the internal ones are from «thick»;

b) a single-layer panel made from «thick» fibers $(6-10 \mathrm{~mm})$;

c) a double-layer panel made from «thin» fibers, perpendicular arrangement;

d) a single-layer panel made from «thin» fibers $(1-5 \mathrm{~mm})$.

All types of panels were made both with the use of urea formaldehyde (UF) and phenol-formaldehyde (PF) resin, Fig. 3.

The panels fabricated by the pressing method were used to produce samples to determine the density, water absorption, strength limit, elasticity module at bending, as well as the above technological properties.

After establishing a priority binder, based on the analysis of the results from an experimental study into the properties of the new composite material, we carried out a second stage of the experimental research. Table 1 gives the panels made during the experiment (Table 1).

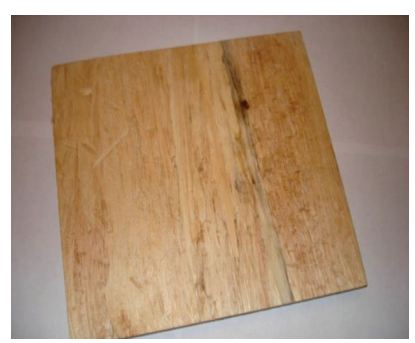

$a$ b

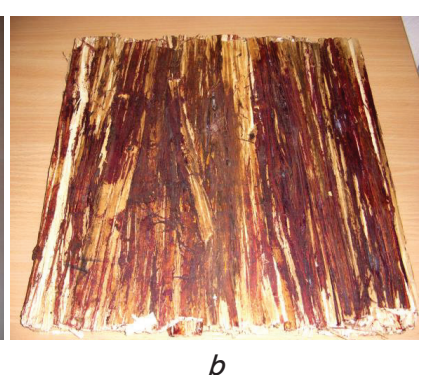

Fig. 3. The panels made using the following binder: $a$ - urea formaldehyde resin, $b$ - phenol-formaldehyde resin
Table 2

Designation of panels with a different structure

\begin{tabular}{|c|l|}
\hline Designation & \multicolumn{1}{|c|}{ Panel structure } \\
\hline Type I & $\begin{array}{l}\text { A three-layer panel made from «thin» fi- } \\
\text { bers }(1-5 \mathrm{~mm})\end{array}$ \\
\hline Type II & $\begin{array}{l}\text { A three-layer panel made from «thick» fi- } \\
\text { bers }(6-10 \mathrm{~mm})\end{array}$ \\
\hline Type III & $\begin{array}{l}\text { A three-layer panel; outer layers are made } \\
\text { from «thin» fibers; internal layers are made } \\
\text { from «thick» fibers }\end{array}$ \\
\hline Type IV & $\begin{array}{l}\text { A three-layer panel, outer layers are made } \\
\text { from «thick» fibers; internal layers are made } \\
\text { from «thin» fibers }\end{array}$ \\
\hline
\end{tabular}

The choice of a three-layer panel is substantiated by the need to obtain a new composite material with the same physical and mechanical properties both in the direction of the longitudinal axis and in the direction of the perpendicular axis.

\section{Research results}

5.1 . The study results on determining a priority binder

The experimental results were statistically treated according to the procedure given in [17]. The results of the statistical treatment of measuring the density of the obtained panels are given in Table 2.

Table 2

The density of the panels' samples with a different binder

\begin{tabular}{|c|c|c|c|c|}
\hline $\begin{array}{c}\text { Binder } \\
\text { type }\end{array}$ & $\begin{array}{c}\text { Mean density } \\
\text { value, } \\
\rho_{a v}, \mathrm{~kg} / \mathrm{m}^{3}\end{array}$ & $\begin{array}{c}\text { Standard } \\
\text { error, } P, \%\end{array}$ & $\begin{array}{c}\text { Standard } \\
\text { deviation, } \\
S, \mathrm{~kg} / \mathrm{m}^{3}\end{array}$ & $\begin{array}{c}\text { Variance } \\
\text { factor, } V, \%\end{array}$ \\
\hline $\mathrm{UF}$ & 640 & 5.424 & 50.29 & 7.42 \\
\hline $\mathrm{PF}$ & 665 & 5.739 & 51.33 & 7.72 \\
\hline
\end{tabular}

The average density of the composite material is close to the OSB panels $\left(\rho_{O S B}=650 \mathrm{~kg} / \mathrm{m}^{3}\right)$. This has allowed us to further compare the physical and mechanical properties of the obtained wood-composite material and OSB panels.

When studying moisture absorption, the panels based on UF were destroyed (Fig. 4).

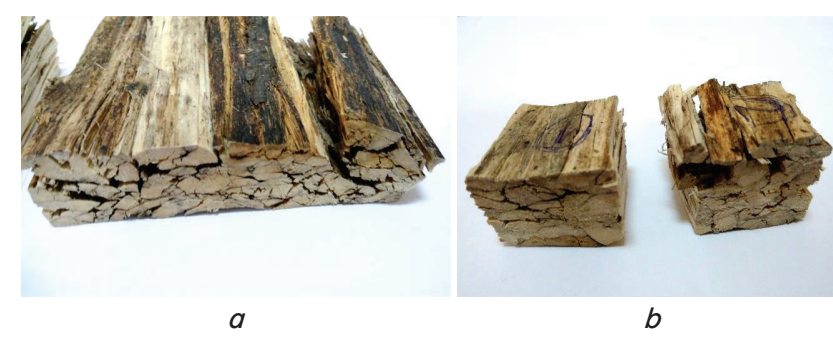

Fig. 4. Samples of a new composite material based on the UF binder after holding in water: $a$ - over 2 hours \pm 5 minutes; the sample size, $25 \times 25 \times 15 \mathrm{~mm} ; b-$ over 24 hours $\pm 15 \mathrm{~min}$; the sample size, $100 \times 100 \times 15 \mathrm{~mm}$

The obtained results of determining the tensile strength at bending (Fig. 5), impact viscosity (Fig. 6), and the specific resistance against pulling out nails (Fig. 7), also testify to the advantage of using a phenol-formaldehyde binder. 


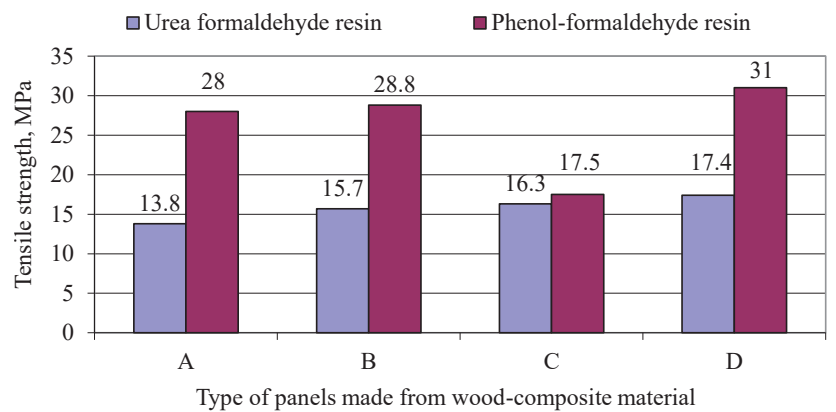

Fig. 5. Mean values of tensile strength at bending for different types of panels made by using a urea formaldehyde or phenol-formaldehyde binder

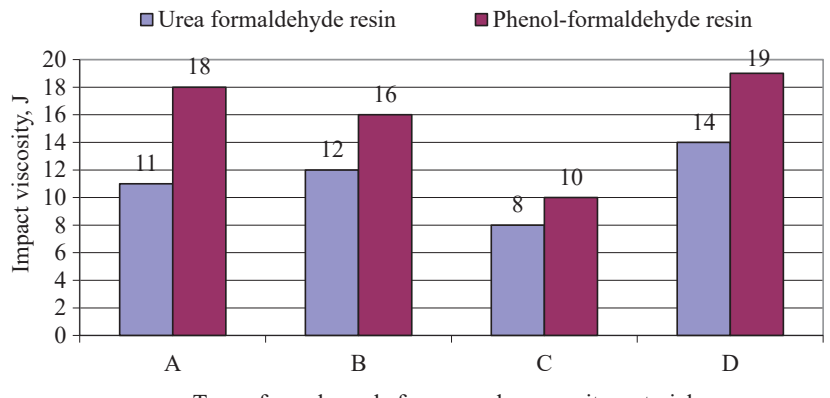

Type of panels made from wood-composite material

Fig. 6. Mean values of impact viscosity fir different types of panels made by using a urea formaldehyde or phenol-formaldehyde binder

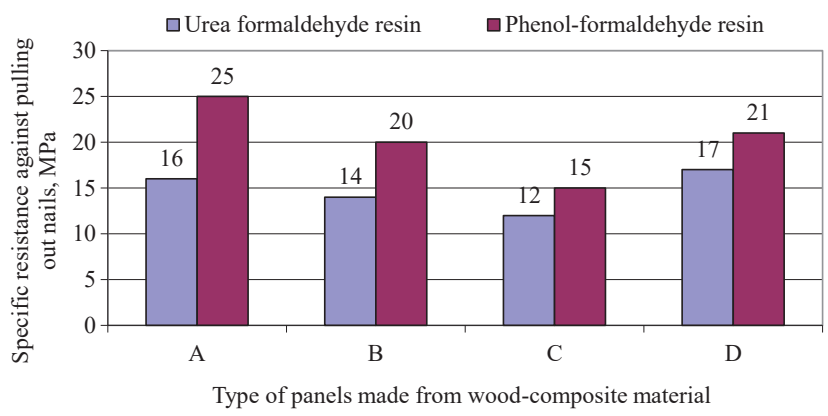

Fig. 7. Mean values of specific resistance against pulling out nails for different types of panels made by using a urea formaldehyde or phenol-formaldehyde binder

An analysis of the obtained results has proven the inappropriate use of a UF binder and the parallel fiber arrangement in a panel. Therefore, it was decided to carry out a second stage of the experimental study, which implied determining a combination of the sizes of weaving in the three-layer panels with a perpendicular arrangement of fibers, as well as defining their mechanical properties.

5. 2. Results of studying the parameters of the wood component obtained by a flattening method and the technological stages in manufacturing the wood-composite material on their basis

In the second stage of our study, we determined the expediency of using different sizes of fibers in the panels based on PF. To this end, we experimentally studied the strength and elasticity module at bending, Fig. 8.

The wood of a trunk and the branches is a set of natural polymers, which consist of long flexible chain molecules. This feature of the polymer structure determines the special character of their behavior under load at pressing. When applying efforts, a polymer during pressing undergoes the following types of deformations: elastic - due to a reverse change in the average values of interparticle distances; plastic - connected with a reversible regrouping of particles (the links of the chain molecules), thus the volume of the body does not change; the elastic ones are due to the irreversible displacement of the molecular chains, the body volume also does not change in this case.
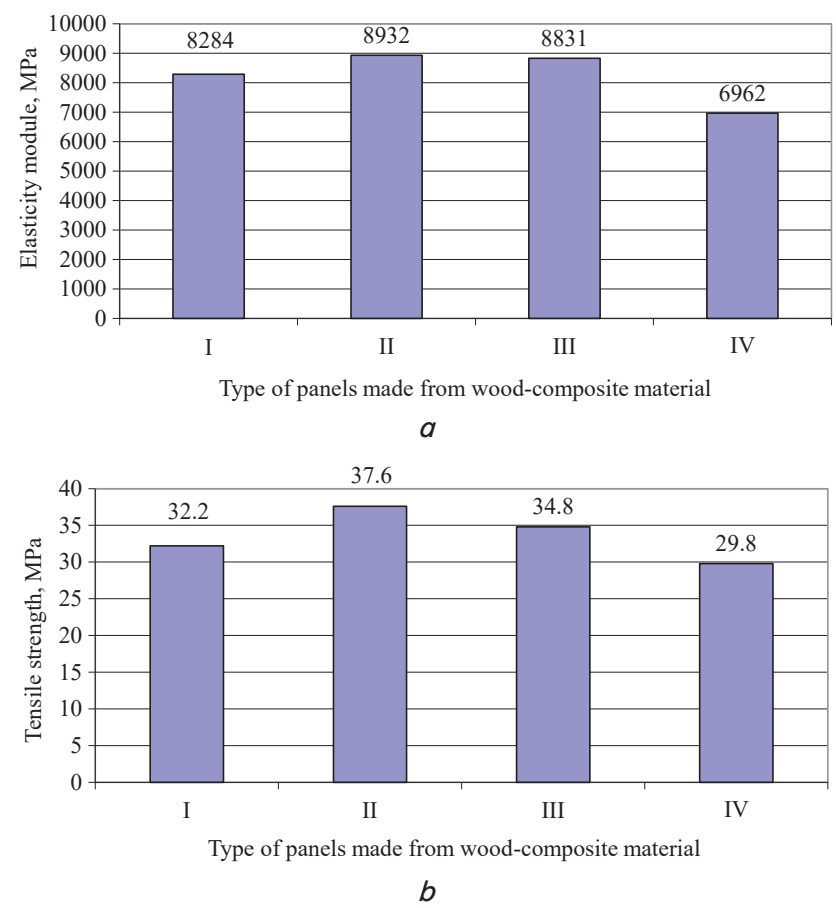

Fig. 8. Mean values of the mechanical properties of the samples of panels made from poplar branches: $a$ - elasticity module at bending; $b-$ strength at bending

The rheological processes in wood occur as follows - at the instantaneous loading by a constant force, there occur, at the same time, the elastic $\varepsilon_{e}$ and plastic $\varepsilon_{p}$ deformations. Over time, the flexible $\varepsilon_{f}$ deformations develop. After removing the load, the elastic deformations restore quickly, the plastic ones - after some time. The recovery process proceeds slower than at loading, so, after the load time is over, the flexible deformations do not have time to fully recover [14].

The total deformation of wood due to loading can be represented as the sum of the deformations $\varepsilon_{e}, \varepsilon_{p}, \varepsilon_{f}$ :

$$
\varepsilon=\varepsilon_{e}+\varepsilon_{p}+\varepsilon_{f},
$$

where $\varepsilon_{e}=\sigma / E$ are the elastic deformations; $\varepsilon_{p}=\sigma / E^{\prime}$ are the plastic deformations;

$$
\varepsilon_{f}=\frac{\sigma}{E_{2}} \cdot\left(1-\varepsilon^{-E_{2} * \frac{\tau}{\eta_{2}}}\right)
$$

- flexible deformations; $\sigma$ - loading, $\mathrm{N} / \mathrm{m}^{2} ; \tau$ - the time a wood sample is exposed to loading, s; $E$ - elasticity module, $\mathrm{N} / \mathrm{m}^{2} ; E^{\prime}$ - plastic deformation module, $\mathrm{N} / \mathrm{m}^{2} ; E_{2}-$ flexible deformation module; $\eta_{2}$ - flexibility factor.

According to [18], the magnitude of plastic deformation is insignificant and is not more than $3 \%$ of the total deformation magnitude, so it can be neglected. 
Given that the magnitude of deformation is influenced by the pressing modes: $p$ - pressure; $t$ - temperature; $\tau$ - aging time under pressure, the rheological model of the pressed material takes the following form:

$$
\varepsilon=\varepsilon_{e}\left(P, T, \tau_{\text {aging }}\right)+\int_{\tau_{\min }^{r l e}}^{\tau_{\max }^{r e l}} \varepsilon\left(P, T, \tau_{\text {agimg }}\right) \mathrm{d} \tau^{r e l} .
$$

To determine the rational parameters of pressing modes that provide for the minimal panel deformity, the intervals of factor variability were selected (Table 3 ) and a series of experimental studies were performed according to the matrix of the complete factor planning (CFP) of experiment $2^{3}$ (Table 4).

Table 3

Factor variance intervals

\begin{tabular}{|c|c|c|c|c|}
\hline \multicolumn{2}{|c|}{ Factor } & \multicolumn{3}{c|}{ Factor variance interval } \\
\hline Natural & Normalized & -1 & 0 & +1 \\
\hline$t,{ }^{\circ} \mathrm{C}$ & $x_{1}$ & 160 & 180 & 200 \\
\hline$p, \mathrm{MPa}$ & $x_{2}$ & 8 & 10 & 12 \\
\hline$\tau, \min$ & $x_{3}$ & 6 & 7 & 8 \\
\hline
\end{tabular}

Table 4

Matrix of the complete factor planning (CFP) of experiment $2^{3}$

\begin{tabular}{|c|c|c|c|c|c|c|c|c|c|c|c|c|}
\hline No. & $X_{0}$ & $X_{1}$ & $X_{2}$ & $X_{3}$ & $X_{1} X_{2}$ & $X_{1} X_{3}$ & $X_{2} X_{3}$ & $X_{1} X_{2} X_{3}$ & $\begin{array}{c}\tau, \\
{ }^{\circ} \mathrm{C}\end{array}$ & $\begin{array}{c}p, \\
\mathrm{MPa}\end{array}$ & $\begin{array}{c}\tau, \\
\mathrm{min}\end{array}$ & $\begin{array}{c}\varepsilon_{a v}, \\
\mathrm{~mm}\end{array}$ \\
\hline 1 & 1 & 1 & 1 & -1 & 1 & -1 & -1 & -1 & 200 & 12 & 8 & 3.75 \\
\hline 2 & 1 & -1 & 1 & -1 & -1 & 1 & -1 & 1 & 160 & 12 & 8 & 3.46 \\
\hline 3 & 1 & 1 & -1 & -1 & -1 & -1 & 1 & 1 & 200 & 8 & 8 & 2.4 \\
\hline 4 & 1 & -1 & -1 & -1 & 1 & 1 & 1 & -1 & 160 & 8 & 8 & 4.27 \\
\hline 5 & 1 & 1 & 1 & 1 & 1 & 1 & 1 & 1 & 200 & 12 & 6 & 3.74 \\
\hline 6 & 1 & -1 & 1 & 1 & -1 & -1 & 1 & -1 & 160 & 12 & 6 & 6.23 \\
\hline 7 & 1 & 1 & -1 & 1 & -1 & 1 & -1 & -1 & 200 & 8 & 6 & 2.17 \\
\hline 8 & 1 & -1 & -1 & 1 & 1 & -1 & -1 & 1 & 160 & 8 & 6 & 3.36 \\
\hline
\end{tabular}

A regression equation was built:

$$
\varepsilon=3.67-0.66 x_{1}+0.62 x_{2}+0.49 x_{2} x_{3}-0.43 x_{1} x_{2} x_{3} \text {, }
$$

The coefficient $b_{i}$ in the regression equation was considered insignificant when the condition [17] was met:

$$
\left|b_{i}\right| \leq t_{\text {tabl }} * S\left\{b_{i}\right\}
$$

where $t_{t a b l}=1.99$ is the Student $t$-criterion at the significance level $q=0.05$ and the number of degrees of freedom $f(y)=N^{*}(n-1)=8^{*}(10-1)=72 ; S\left\{b_{i}\right\}$ is the standard deviation in the regression equation coefficients; $N=8$ is the number of experiments; $n=10$ is the number of duplicated experiments.

Variance: in the reproducibility $S^{2}\{y\}$, in the coefficients of the regression equations $S^{2}\left\{b_{i}\right\}$, and the adequacy $S_{a d}^{2}$ was determined from the following formulas [17]:

$$
\begin{aligned}
& S^{2}\{y\}=\frac{E_{j}^{8} S_{j}^{2}}{N}=2.44, \\
& S^{2}\left\{b_{i}\right\}=\frac{S^{2}\{y\}}{n^{*} N}=0.030,
\end{aligned}
$$

$$
S_{a d}^{2}=n^{*} \frac{\sum_{j=1}^{n}\left(\bar{y}_{j}-\widehat{y}_{j}\right)^{2}}{N-p}=4.75,
$$

where $S_{J}^{2}$ is the variance of the $j$-th experiment; $\bar{y}_{j}$ is the average value of the output parameter in the $j$-th series of experiments; $\hat{y}_{j}$ is the value of the output parameter in the $j$-th series of experiments, calculated from the regression equation; $p=5$ is the number of significance coefficients in the regression equation.

The estimated value of a Fisher criteria:

$$
F_{c a l}=\frac{S_{a d}^{2}}{S^{2}\{y\}}=2.60 \text {. }
$$

Using the $F$-distribution tables for $q=0.05$ and at the number of degrees of freedom $f_{a d}=N-p=8-5=3$ and $f_{y}=$ $=N \cdot(n-1)=72$, we derived the value $F_{t a b}=2.74$ [17].

The adequacy test of regression equation (4) based on the Fisher criterion $F_{c a l}=2.60<F_{t a b}=2.74$ confirmed the correspondence of the regression model to the experimental data.

The results of calculating the panel deformation magnitude after pressing under different schedules are shown in Fig. 9.

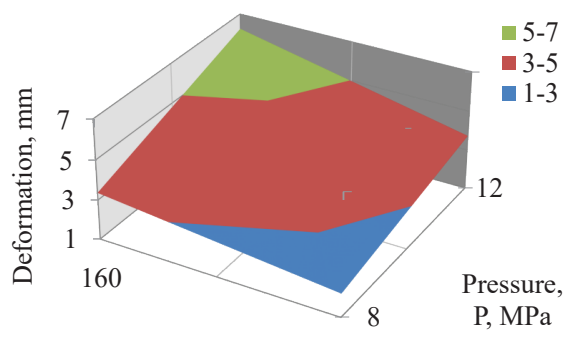

Temperature, $\mathrm{T},{ }^{\circ} \mathrm{C} \quad 200$ $\mathrm{MPa}$

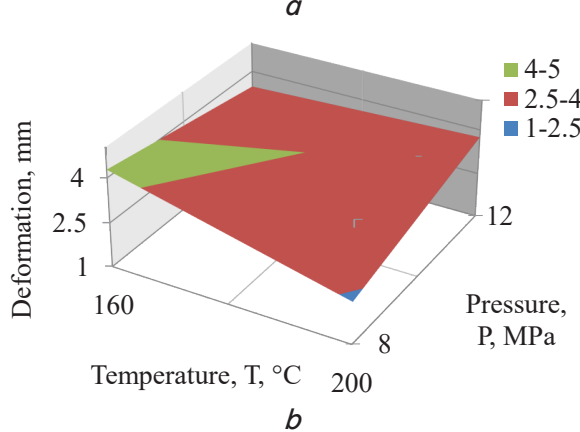

Fig. 9. Dependence of the deformation magnitude of composite material on temperature and pressure for the following holding: $a-7 \mathrm{~min} ; b-8 \mathrm{~min}$

At the same pressure and temperature of the press panels, smaller deformations are observed in the case of a less holding time under load.

\section{3. Determining a shape stabilization time of the pan-} els made from a new wood-composite material

To determine the rational schedule of pressing the woodcomposite material, one must know the duration of a material's shape stabilization after the stresses arising at pressing. Because elastic deformations disappear quickly enough, the residual deformation magnitude is determined mainly by flexible deformations. Given (2), it is possible to determine the thermal stabilization time.

To calculate $\tau=f\left(e_{e}\right)$, we performed a transformation. 
Denote:

$$
\frac{\sigma}{E}=A ; \quad \frac{E_{2}}{\eta_{2}}=B
$$

where $\eta_{2}$ is the coefficient of flexibility equal to the ratio of the thickness $h$ to the length $l$ of the sample and is $\eta_{2}=0.05$ :

$$
\eta_{2}=\frac{h}{l}
$$

Then:

$$
\varepsilon_{e}=A\left(1-e^{-B * \tau}\right)
$$

where $\varepsilon_{e}$ is the relative elasticity, which equals $\varepsilon_{e_{\max }} / \varepsilon_{e_{c}}$

The time of shape stabilization can be determined from the following expression:

$$
\tau=\ln \left(\sqrt[B]{1-\frac{\varepsilon_{e}}{A}}\right)=\ln \left(\frac{1}{\left(1-\frac{\varepsilon_{e} * E_{2}}{\sigma}\right)^{\frac{1}{0.05}}}\right) .
$$

Thus, depending on the schedule of pressing, it is possible to determine a material's shape stabilization time (Fig. 10) and choose the schedule that provides for the minimum holding.

Equation (12) was used to calculate the value of a shape stabilization time for the panels made from wood-composite material for different modes of pressing - Fig. 11.

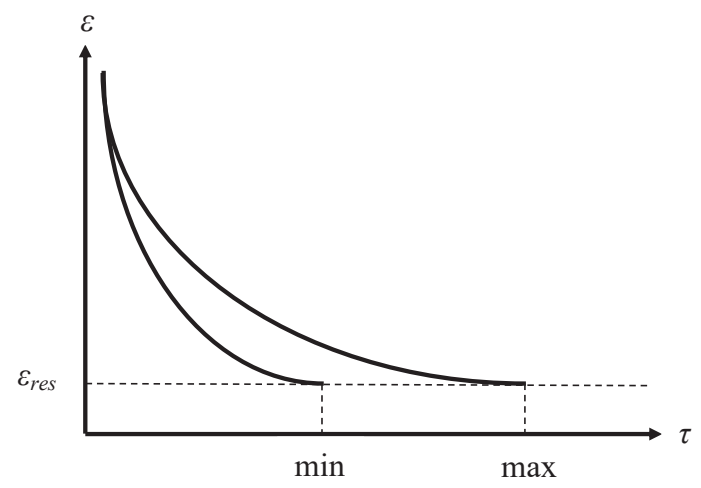

Fig. 10. The principle of determining the time of shape stabilization $\varepsilon_{\text {res }}$

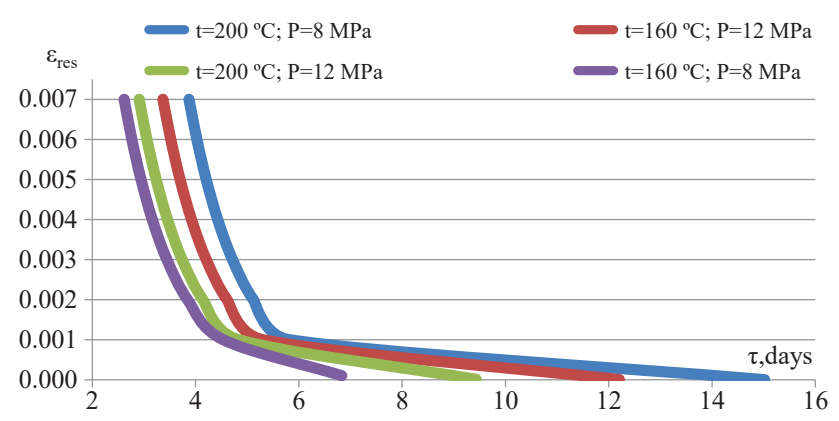

Fig. 11. Mean values of a shape stabilization duration of the wood-composite material under different schedules of pressing

The smallest shape stabilization time, 7 days, was demonstrated by the samples of panels pressed at temperature $t=200{ }^{\circ} \mathrm{C}$ and pressure $p=8 \mathrm{MPA}$, which agrees with the results obtained when determining the deformity of a panel as a result of pressing.

\section{Discussion of results of determining the properties of the new wood-composite material made from logging waste}

Based on the results of our experimental study, a new wood-composite material was obtained [13] with the similar physical, and even better mechanical, properties compared to OSB panels. Thus, the density of the new material is $\rho_{n m}=665 \mathrm{~kg} / \mathrm{m}^{3}$ (Table 3), the density of OSB panels is $\rho=650 \mathrm{~kg} / \mathrm{m}^{3}$ [10]. The tensile strength at bending of the new material was - 29.8-37.6 MPa (Fig. 8, $b$ ), that of the OSB panels of general purpose - 9-17 MPa and 26-30 MPa (for panels of increased strength). The elasticity module of the new composite material at bending was 6,962-8,932 MPa (Fig. 8, $a$ ), that of the OSB panels of general purpose $-2,500 \mathrm{MPa}$ and $4,800 \mathrm{MPa}$ (for panels of increased strength). It is found that the values of the tensile strength and the elasticity module for the first three groups of sample panels are approximately the same. In the fourth sample group, these indicators are $20 \%$ lower (Table 2). This is due to the use of thin fibers in the middle layer of the material that do not provide the adequate strength and elasticity of the material. Therefore, to facilitate the technological process and reduce its cost in the manufacture of the new wood-composite material, one can recommend the use of fibers of equal thickness, $6-10 \mathrm{~mm}$.

The high values of the mechanical properties of the new wood-composite material are explained by the properties of a wood components. In contrast to OSB panels and other wood-composite materials, it is proposed to fabricate a wood component not by crushing but flattering. Wood fibers when flattered are not crushed along the length, as is the case in the production of OSB panels, they retain their natural strength, which ensures the high mechanical properties of a material, similar to massive timber. To obtain a wood fiber of the predefined parameter, branches are flattered, that is, they are rolled through the profiled rollers under pressure at a special installation. Because the weave thickness of $6-10 \mathrm{~mm}$ is considerably larger than the wood particles used in the manufacture of OSB panels, 2-6 mm, the energy consumption for the wood component production is smaller. In addition, the technological process of OSB panel fabrication requires the use of wood raw materials in the form of trunks, which are used in other technological processes - the manufacture of paper, cellulose, fuel materials, which is accompanied by competition in the acquisition of the raw materials. Meanwhile, in the felling areas, there remains a significant amount of logging waste: branches, knots, tree tops, which are still not utilized in the industry.

Our study involved the branches of poplar as a fast-growing wood species. Meanwhile, it does not belong to industrial timber and its plantations are still insignificant. Therefore, further research will employ the branches of pine as the most widespread wood type in our country. In addition, it is a relevant task to search for a non-harmful binder to achieve the complete environmental friendliness of the proposed material.

As regards the peculiarities of the technological process of manufacturing the new wood-composite material, which is a little shorter compared to the production of OSB panels, it eliminates such stages as peeling ridges, cutting of splinters, chip sorting. Further technological operations, such as drying, tarring, carpet forming and pressing, as well as the equipment for their implementation, are similar.

Thus, by using the wood raw materials unclaimed by the industry, one can obtain such wood-composite panels that are not inferior in its properties to the OSB panels. 


\section{Conclusions}

1. The result of our study is the established possibility to use logging waste for the manufacture of wood-composite panels. The peculiarity of the new wood-composite material is the application of a wood component made from whole woody fibers obtained by flattening the poplar branches. Based on the experimental research into the techniques for arranging fibers with different sizes of the weaving elements and the type of a binder, it is determined that the use of the urea formaldehyde binder is inappropriate. It is explained by the fact that the products made from it are not water-resistant and have $20 \%$ lower rates of mechanical properties than the panels containing phenol-formaldehyde resin. In addition, we determined the inappropriate use of the single-layer and double-layer materials for the manufacture of panels because they lose their flat shape immediately after pressing.

2 . The experimental study of the physical, mechanical, and technological properties of the new wood-composite material allowed us to determine its rational parameters: the thickness of a wood fiber, 6-10 mm; the type of a binder - phenol-formaldehyde resin; a three-layer structure with mutually perpendicular fiber arrangement. The adequate regression models have been derived for the dependence of wood-composite panels' deformity on the parameters of pressing schedules - the temperature, pressure, and holding time under pressure. That has made it possible to determine the rational pressing schedule, under which one can achieve the minimum deformation of panels after pressing, and the time of shape stabilization: temperature, $t=200{ }^{\circ} \mathrm{C}$; pressure, $p=8 \mathrm{MPa}$; time, $\tau=7 \mathrm{~min}$.

3 . The experimentally defined values of the tensile strength and elasticity module at bending of the resulting material are larger by 25 and $77 \%$, respectively, than the same indicators for OSB panels of increased strength. Consequently, the proposed new material can become an alternative to OSB panels both in terms of a cost component and the simplified technological process. The efficiency of the use of wood-composite panels made from flattened branches implies the improved ecological condition of felling areas and a better utilization of wood raw materials.

\section{References}

1. Skliar, D., Smirdriakova, M., Sedliacik, J. (2017). Selected physical and mechanical properties of plywood faced with wood slices. Acta Facultatis Xylologiae, 59 (1), 97-105. doi: http://doi.org/10.17423/afx.2017.59.1.09

2. Aydin, I., Demirkir, C., Colak, S., Colakoglu, G. (2016). Utilization of bark flours as additive in plywood manufacturing. European Journal of Wood and Wood Products, 75 (1), 63-69. doi: https://doi.org/10.1007/s00107-016-1096-0

3. Bekhta, P., Ortynska, G., Sedliacik, J. (2014). Properties of Modified Phenol-Formaldehyde Adhesive for Plywood Panels Manufactured from High Moisture Content Veneer. Drvna Industrija, 65 (4), 293-301. doi: https://doi.org/10.5552/drind.2014.1350

4. Nam, S., Netravali, A. N. (2006). Green composites. II. Environment-friendly, biodegradable composites using ramie fibers and soy protein concentrate (SPC) resin. Fibers and Polymers, 7 (4), 380-388. doi: https://doi.org/10.1007/bf02875770

5. Konnerth, J., Hahn, G., Gindl, W. (2009). Feasibility of particle board production using bone glue. European Journal of Wood and Wood Products, 67 (2), 243-245. doi: https://doi.org/10.1007/s00107-009-0307-3

6. Kusumah, S. S., Arinana, A., Hadi, Y. S., Guswenrivo, I., Yoshimura, T., Umemura, K., Tanaka, S., Kanayama, K. (2017). Utilization of Sweet Sorghum Bagasse and Citric Acid in the Manufacturing of Particleboard. III: Influence of Adding Sucrose on the Properties of Particleboard. BioResources, 12 (4), 7498-7514.

7. Voitovych, I. H. (2010). Osnovy tekhnolohiyi vyrobiv z derevyny. Lviv: Nats. lisotekhn. un-t Ukrainy, 304.

8. Migneault, S., Koubaa, A., Erchiqui, F., Chaala, A., Englund, K., Wolcott, M. P. (2009). Effects of processing method and fiber size on the structure and properties of wood-plastic composites. Composites Part A: Applied Science and Manufacturing, 40 (1), 80-85. doi: https://doi.org/10.1016/j.compositesa.2008.10.004

9. Madyan, O. A., Wang, Y., Corker, J., Zhou, Y., Du, G., Fan, M. (2020). Classification of wood fibre geometry and its behaviour in wood poly(lactic acid) composites. Composites Part A: Applied Science and Manufacturing, 133, 105871. doi: https://doi.org/ 10.1016/j.compositesa.2020.105871

10. BS EN 300:2006. Oriented strand boards (OSB). Definitions, classification and specification.

11. Ashori, A., Sheshmani, S. (2010). Hybrid composites made from recycled materials: Moisture absorption and thickness swelling behavior. Bioresource Technology, 101 (12), 4717-4720. doi: https://doi.org/10.1016/j.biortech.2010.01.060

12. Annienkov, V. F., Hroshev, Yu. M. (1998). Povnotsinnyi zaminnyk naturalnoi derevyny. Svit mebliv ta paperu, 1, 10-15.

13. Pinchevska, O., Lakyda, Y. (2013). On importance of characteristics of wood component of composition materials. Adhesives in woodworking industry: XXI Symposium, 178-181.

14. BS EN 323:1993. Wood-based panels. Determination of density.

15. BS EN 317:1993. Particleboards and fibreboards. Determination of swelling in thickness after immersion in water.

16. BS EN 310:1993. Wood-based panels. Determination of modulus of elasticity in bending and of bending strength.

17. Pizhurin, A. A., Rozenblit, M. S. (1984). Issledovaniya protsessov derevoobrabotki. Moscow: Lesnaya prom-st', 232.

18. Kollmann, F. F. P., Kuenzi, E. W., Stamm, A. J. (1975). Principles of Wood Science and Technology. II Wood Based Materials. Springer. doi: https://doi.org/10.1007/978-3-642-87931-9 